\title{
The influence of nanosized iron particles on morphological parameters of blood and reproductive ability of sows in the third trimester of gestation
}

\author{
Lydia Kashirina*, Vitaly Kulakov, Elman Saitkhanov, and Sergey Denikin \\ Ryazan State Agrotechnological University named after P.A. Kostychev, 390044 Ryazan, Russia
}

\begin{abstract}
The article presents the results of experimental studies on the use of nanosized iron powder in the third trimester of gestation on the reproduction processes of sows. The studies were carried out in the conditions of the farm. The physiological state of pregnant sows was determined by hematological parameters. It was found that iron NRP contributed to an increase in the number of red blood cells and hemoglobin in the blood of sows, compared with the control 20 days before farrowing, the content of red blood cells in the blood of experimental sows was $6.3 \%$ significantly higher compared to the control, and hemoglobin by $3.8 \%$. For 10 days, before farrowing, respectively, by $6.9 \%$ and $5.2 \%$ higher. The indicators that characterize the reproductive ability of sows are: multiplicity, large fertility, the number of piglets in the nest and their average live weight. The use of ultrafine iron powder in the diets of pregnant sows in the third trimester of gestation contributed to the improvement of the overall physiological state, confirmed by the improvement of hematological parameters and had a positive effect on reproductive ability. The weight of the nest in the experimental group of sows on the day of farrowing was $4.1 \%$ higher, the large-fruiting rate was $3.1 \%$, compared to the control animals.
\end{abstract}

In modern conditions of livestock breeding, special attention is paid to increasing the production of meat products to fully meet the needs of the population, that is mainly solved through the production of pork, since pigs are early maturing and multiple animals [1-3].

Pregnant sows are sensitive to the lack of mineral and vitamin components of the diet, on which depends not only their health, but also the offspring obtained [1,2]. The use of various feed and biologically active additives, which are an additional source of minerals and vitamins, compensates for its lack in the body of animals, improves metabolic processes, increases productivity, has a positive effect on fertility, embryonic development of offspring, and reduces the impact of stress factors [4-6].

When using biologically active additives, it is possible to correct many biochemical processes and the state of defense mechanisms in the body [7].

\footnotetext{
*Corresponding author: kashirina@rgatu.ru
} 
Currently, more attention is paid to the use of metal nanoparticles (NPs) as biologically active substances in animal husbandry. According to a number of scientists [7], these substances have high biological activity and are capable of influencing the system of regulation of trace elements at the cellular level.

Such metals as iron, cobalt and copper are the most important trace elements, since they take part in the processes of hematopoiesis, and thereby ensure the normalization of physiological processes in the body of animals.

Good quality products can only be obtained from healthy animals, so the health of mothers is fundamental to the production of viable offspring. It is known that the milk of sows has a low iron content, which does not meet the requirements of sucking piglets for a trace element. In this regard, they have metabolic disorders and, as a result, develop iron deficiency anemia. The disease is characterized by a disorder of the function of hematopoietic organs, a violation of metabolic processes, and this affects the growth retardation of young animals and a decrease in resistance $[1,4,6]$.

The main indicators assessing the reproductive capacity of sows include multiple births, large prolificacy, the number of piglets in the kit, the average live weight of piglets, the total weight of piglets and the milk production of mothers.

The aim of the research was to study the effect of nanosized iron particles on the reproductive ability and productivity of sows in the third trimester of gestation $[1,3]$.

The studies were carried out in the conditions of JSC Ryazan Bacon in Pronsky district of Ryazan region. The studies concerned 6 hybrid sows-analogs of the 2nd farrowing of the large white breed $\times$ duroc, which were in the third trimester of gestation. The animals were formed into two groups of 3 heads: control and experimental. The animals of the control group received the main diet. Experimental sows, got iron NPs in addition to the basic diet at a dose of $0.08 \mathrm{mg} / \mathrm{kg}$ of live weight in an ultrafine state, with which the concentrate part of the diet was processed.

The conditions for keeping the animals were the same. Each animal was housed in an individual cage in a sow house. Feeding was carried out manually, 2 times a day and the type of feeding was concentrate. The feeding rations were balanced in terms of nutrients in accordance with the norms and fully satisfied physiological needs of the body of pregnant sows [8]. In the first half of gestation, the diet contained $3.4 \mathrm{~kg}$ fodder unit and $375 \mathrm{~g}$ of digestible protein, and in the second half it included $3.8 \mathrm{~kg}$ fodder unit and $440 \mathrm{~g}$ of digestible protein.

The large size of sows was determined by the average live weight of the kit at the time of birth.

Prolificacy is the number of piglets in the kit, considering the number of viable and stillborn piglets.

Four days before farrowing, the rate of all feed consumed by pregnant sows was reduced by 2 times to reduce the load on digestive organs and prevent premature milk formation.

The physiological state of pregnant sows was determined by hematological parameters (Table 1). It was found that iron NPs promoted an increase in the number of erythrocytes and hemoglobin in the blood of sows, compared with the control. 20 days before farrowing, the content of erythrocytes in the blood of the experimental sows was $6.3 \%$ significantly higher compared to the control, and hemoglobin was $3.8 \%$ higher. 10 days before farrowing the parameters were $6.9 \%$ and $5.2 \%$ higher, respectively. 
Table 1. Hematological parameters of pregnant sows $(n=6)$

\begin{tabular}{|c|c|c|c|c|}
\hline \multirow{2}{*}{ Parameter } & \multirow{2}{*}{ Group } & \multicolumn{3}{|c|}{ Days of research before farrowing } \\
\cline { 2 - 5 } & & 30 & 20 & 10 \\
\hline \multirow{2}{*}{ Hemoglobin, g/l } & Control & $97.8 \pm 1.58$ & $97.6 \pm 1.61$ & $99.3 \pm 1.06$ \\
\cline { 2 - 5 } & Experiment & $97.9 \pm 1.27$ & $101.4 \pm 1.26^{*}$ & $104.8 \pm 1.57 * *$ \\
\hline \multirow{2}{*}{$\begin{array}{c}\text { Erythrocytes, } \\
10^{12} / \mathrm{l}\end{array}$} & Control & $6.59 \pm 0.20$ & $6.53 \pm 0.18$ & $6.65 \pm 0.23$ \\
\cline { 2 - 5 } & Experiment & $6.64 \pm 0.19$ & $6.94 \pm 0.14^{*}$ & $7.14 \pm 0.16^{*}$ \\
\hline \multirow{2}{*}{ ESR, mm/hour } & Control & $4.40 \pm 0.61$ & $4.60 \pm 0.62$ & $4.20 \pm 0.42$ \\
\cline { 2 - 5 } & Experiment & $4.30 \pm 0.62$ & $4.00 \pm 0.89$ & $3.90 \pm 0.61$ \\
\hline \multirow{2}{*}{ Leukocytes, $10^{9} / 1$} & Control & $9.97 \pm 0.43$ & $9.97 \pm 0.48$ & $10.25 \pm 0.24$ \\
\cline { 2 - 5 } & Experiment & $9.78 \pm 0.47$ & $10.30 \pm 0.38$ & $10.82 \pm 0.35^{*}$ \\
\hline \multirow{2}{*}{ Platelets, $10^{9} / 1$} & Control & $208.20 \pm 3.20$ & $208.60 \pm 5.81$ & $209.40 \pm 6.62$ \\
\cline { 2 - 5 } & Experiment & $207.80 \pm 4.34$ & $207.40 \pm 4.14$ & $209.40 \pm 4.62$ \\
\hline
\end{tabular}

Note: hereinafter $-{ }^{*} \mathrm{p}<0.05 ;{ }^{* *} \mathrm{p}<0.01$ in relation to the control group

The use of iron NPs in the diets of experimental animals activated the function of hematopoiesis, that was manifested in an increase in the content of erythrocytes and leukocytes, an increase in the level of hemoglobin (Table 1). This fact made it possible to judge about the improvement of gas, water-salt metabolism in the body of experimental sows, acceleration of the transport of adsorbed nutrients to cells, and stabilization of blood $\mathrm{pH}$.

ESR is one of the important indicators that control the physiological state of pregnant sows. ESR in the experimental group of sows was lower than in the control and decreased by the period of farrowing. Obviously, this happened under the influence of iron, which was additionally received by the experimental animals. By the time of childbirth, it was 7.2 $\%$ lower in the experimental animals, then in the control, that indicated the normalization of physiological processes associated with an increase in the number of young erythrocytes, and, as a consequence, a decrease in the average volume of erythrocytes in the blood, which indicated the stability of their negative charge and the constancy of the blood viscosity index.

The total number of leukocytes to the period of delivery increased in both groups, but in the experimental group this process occurred with a gradual increase, which was $5.6 \%$ higher than in the control 10 days before delivery. The number of platelets in the blood of control and experimental animals throughout the experiment was within the physiological norm, but 10 days before farrowing, a slight increase was observed in all groups, which was due to physiological characteristics of pregnant animals. So, compared with the indicator of 20 days before delivery, the number of platelets in the control and experimental groups increased by $0.6 \%$ and $0.8 \%$, respectively.

Based on this, it can be assumed that an increase in the level of leukocytes and platelets by the end of gestation is a natural property of the sow's body, due to an increase in the function of the immune system before farrowing.

Analysis of the live weight of sows is an important indicator reflecting their ability to reproduce and raise piglets (Table 2 ). 
Table 2. Analysis of the live weight of sows during the experiment, $\mathrm{kg}(\mathrm{n}=6)$

\begin{tabular}{|l|c|c|}
\hline Parameter & Control & Experiment \\
\hline Before the experiment & $169.5 \pm 1.1$ & $169.4 \pm 1.2$ \\
\hline 5 days before farrowing & $192.1 \pm 1.2$ & $194.8 \pm 1.5^{*}$ \\
\hline Increase for 30 days of gestation & $20.8 \pm 1.1$ & $25.5 \pm 1.3^{*}$ \\
\hline 5 days after farrowing & $180.9 \pm 1.6$ & $186.4 \pm 2.3$ \\
\hline Weight loss per farrowing & $9.4 \pm 0.8$ & $8.9 \pm 0.4^{*}$ \\
\hline
\end{tabular}

5 days before farrowing, the sows that received iron NPs had a significantly higher live weight compared to control animals, exceeding it by an average of $1.8 \%(\mathrm{p}<0.05)$. The gain in the live weight of the experimental sows for 30 days of gestation was greater than that of the control sows by $4.7 \mathrm{~kg}(\mathrm{p}<0.05)$, with a smaller loss of $0.5 \mathrm{~kg}$ of the live weight per farrowing.

The reproductive ability of sows was assessed by indicators of prolificacy, large fertility, the number of piglets in the kit, their average live weight.

The average number of piglets when farrowing in the control group of sows 10.2 heads that characterized prolificacy, and animals of the experimental group had 10.3 heads, i.e. the difference was minimal.

The large size of sows was determined by weighing newborn piglets. This indicator was significantly higher in the sows of the experimental group, than that in the control by $3.1 \%$ (Table 3).

The average weight of the kit on the day of farrowing for animals of the experimental group was $4.1 \%$ more than that in the control.

Table 3. Reproductive ability of sows ( $\mathrm{n}=6)$

\begin{tabular}{|l|c|c|}
\hline Parameter & Control & Experiment \\
\hline Prolificacy, heads & $10.2 \pm 0.49$ & $10.3 \pm 0.45$ \\
\hline Kit weight per day of farrowing, kg & $9.13 \pm 0.11$ & $9.51 \pm 0.23$ \\
\hline Large fertility, kg & $0.895 \pm 0.012$ & $0.923 \pm 0.02 *$ \\
\hline
\end{tabular}

Thus, the use of ultrafine iron particles in the diets of pregnant sows in the third trimester of gestation contributed to an improvement in the general physiological state, which was confirmed by an improvement in hematological parameters and had a positive effect on reproductive capacity. The weight of the kit in the experimental group of sows on the day of farrowing was $4.1 \%$ higher and the large fertility was $3.1 \%$ higher than in the control animals.

\section{References}

1. L.G. Kashirina, E.O. Saitkhanov, Dynamics of the live weight of pregnant sows with the introduction of ultrafine iron particles into the diet. Animal Science, 8, pp. 17 (2012)

2. V.V. Kulakov, L.G. Kashirina, Some indicators of blood and productivity of pigs with the introduction of ultrafine iron particles into the diet. Bulletin of Voronezh State Agrotechnological University, 3 (30), pp. 65-67 (2011)

3. V.V. Kulakov, Veterinary and sanitary assessment of the quality of products of slaughter of pigs with the introduction of nanosized iron particles into the diet. Herald 
of Ryazan State Agrotechnological University Named after P.A. Koyatychev, 4 (16), pp. 36-38 (2012)

4. S.A. Denikin, Influence of the frequency of introduction of ultrafine cobalt particles on morphological parameters of blood and weight gain in rabbits. Collection of scientific works of Ryazan State Agrotechnological University. Innovative directions and methods of implementation of scientific research in the agro-industrial complex, Ryazan, pp. 211-213 (2012)

5. I. Kondakova, E. Vologzhanina, J. Lomova, N. Kryuchkova, Causes of diseases of the digestive system of the young cattle. E3S Web of Conferences: International Scientific and Practical Conference «Development of the Agro-lndustrial Complex in the Context of Robotization and Digitalization of Production in Russia and Abroad». Vol. 222. $02013(2020)$

6. A.S. Emelyanova, E.E. Stepura, M.A. Gerasimov, S.D. Emelyanov Mathematical modelling of heart rhythm in dairy cattle. IOP Conference Series: Earth and Environmental Science. Volume 488, Issue 1. - 012014 (2020)

7. G.E. Folmanis, L.V. Kovalenko, Ultrafine metals in agricultural production. Moscow, IMET RAN (1999)

8. A.P. Kalashnikov, V.I. Fisinin, V.V. Shcheglova, N.I. Kleymenova. Norms and rations of feeding agricultural animal, Moscow (2003) 